\author{
Sebastián Iribarren-Diarasarri \\ Felipe Aizpuru-Barandiaran \\ Tomás Muñoz-Martínez \\ Ángel Loma-Osorio \\ Marianela Hernández-López \\ José María Ruiz-Zorrilla \\ Carlos Castillo-Arenal \\ Juan Luis Dudagoitia-Otaolea \\ Sergio Martínez-Alutiz \\ Cristina Vinuesa-Lozano
}

\section{Reply to Vandijck et al.}

Accepted: 19 March 2009

Published online: 3 April 2009

(C) Springer-Verlag 2009

This reply refers to the comment available at: doi:10.1007/s00134-009-1476-6.

First of all we would like to thank Vandijck et al. for their interest in, and their comments on, our article "Health-related quality of life (HRQoL) as a prognostic factor of survival in critically ill patients" [1].

Through a careful analysis of the variables associated to a moderate to severe HRQoL damage prior to admission to the ICU we have found the results outlined in Table 1.

Therefore, HRQoL damage is associated with the following: female gender, chronic lung disease, age, and depression. The association with APACHE II can be explained by the fact that age and chronic lung disease are incorporated into this variable.
However, in our cohort we have not found differences between patients with cancer and those without. In relation to this group of cancer patients, Taccone et al. [2] have recently published a substudy of the Sepsis Occurrence in Acutely Ill Patients (SOAP) study in which 60day survival rates are similar in patients with and without solid cancers. This is not the case with patients with hematologic cancers.

We completely agree that it is necessary to conduct more research into quality of life in critical patients, as the results of our work cannot be measured simply in terms of mortality. This is particularly important when we take into consideration the huge economic costs inherent to a highly technology-intensive discipline such as critical medicine.

Moreover, we consider that it is necessary to quantify our patients' quality of life, just as we quantify other indicators such as APACHE, SAPS, and SOFA. In this sense, we believe quality of life is an additional tool that can help professionals inform patients and their relatives about both their vital and functional prognoses. This tool can also support the decision-making process in situations when life-support treatments may need to be limited. In addition to this, HRQoL is advantageous as it can be quantified prior to the patient's admission to the ICU.

Notwithstanding, we know that there are many patients who would be

Table 1 Association of several clinical and demographic factors with HRQoL

\begin{tabular}{lllr}
\hline & $\begin{array}{l}\text { Prior QL }<8 \\
(n=264)\end{array}$ & $\begin{array}{l}\text { Prior QL } \geq 8 \\
(n=113)\end{array}$ & $P$ \\
\hline Gender (male) & $184(69.7 \%)$ & $64(56.6 \%)$ & 0.014 \\
Age & $59.61 \pm 17.243$ & $67.26 \pm 12.979$ & $<0.001$ \\
Chronic lung disease & $60(22.8 \%)$ & $46(40.7 \%)$ & $<0.001$ \\
Depression & $12(4.5 \%)$ & $16(14.2 \%)$ & 0.001 \\
Cancer & $59(22.4 \%)$ & $20(17.7 \%)$ & 0.3 \\
APACHE II & $15.77 \pm 7.497$ & $19.57 \pm 7.032$ & $<0.001$ \\
\hline
\end{tabular}

Categorical variables are presented as percentages and their association with HRQoL was analyzed using the chi-square test, and normal continuous variables (mean \pm standard deviation) using Student's $t$ test admitted to the ICU despite their minimal chances of survival, causing severe detriment to their quality of life [3]. It would be unfair and socially unjustifiable to use limited resources on patients with minimal or no chances of recovery.

\section{References}

1. Iribarren-Diarasarri S, AizpuruBarandiaran F, Munoz-Martinez T, Loma-Osorio A, Hernandez-Lopez M, Ruiz-Zorrilla JM, Castillo-Arenal C, Dudagoitia-Otaolea JL, Martinez-Alutiz S, Vinuesa-Lozano C (2009) Healthrelated quality of life as a prognostic factor of survival in critically ill patients. Intensive Care Med. doi: 10.1007/s00134-009-1418-3

2. Taccone FS, Artigas AA, Sprung CL, Moreno R, Sakr Y, Vincent JL (2009) Characteristics and outcomes of cancer patients in European ICUs. Crit Care 13:R15

3. Mendelsohn AB, Chelluri L (2003) Interviews with intensive care unit survivors: assessing post-intensive care quality of life and patients' preferences regarding intensive care and mechanical ventilation. Crit Care Med 31:400-406

S. Iribarren-Diarasarri $(\bowtie)$

T. Muñoz-Martínez · Á. Loma-Osorio M. Hernández-López · J. M. Ruiz-Zorrilla · C. Castillo-Arenal · J. L. Dudagoitia-

Otaolea $\cdot$ S. Martínez-Alutiz

C. Vinuesa-Lozano

Intensive Care Unit, Hospital Txagorritxu, Calle Jose Atxotegi s/n. 01009,

Vitoria, Spain

e-mail:

sebastian.iribarrendiarasarri@osakidetza.net

Tel.: +34-945007280

Fax: +34-945007331

F. Aizpuru-Barandiaran Department of Research, Hospital Txagorritxu,

Vitoria, Spain 